\title{
O PAPEL DO DIREITO NA ARTICULAÇÃO GOVERNAMENTAL NECESSÁRIA ÀS POLÍTICAS PÚBLICAS: UMA AVALIAÇÃO DO PROGRAMA BOLSA FAMÍLIA (PBF)
}

the ROLe Of LAW IN GOVERNMENTAL ARTICULATION REQUIRED IN PUBLIC POLICY: EVALUATING THE BOLSA FAMÍLIA PROGRAM

\section{EL PAPEL DEL DERECHO EN ARTICULACIÓN GUBERNAMENTAL NECESARIO A POLÍTICAS PÚBLICAS: UNA EVALUACIÓN DEL PROGRAMA BOLSA FAMILIA}

\section{RESUMO}

Este artigo analisa o Programa Bolsa Família (PBF) na condição de política pública de combate à pobreza, explicitando a articulação da ação dos atores envolvidos e os contornos jurídicos que lhe dão suporte. 0 programa será examinado com base no quadro de referência de políticas públicas proposto por Bucci ("Quadro de referência de uma política pública: Primeiras linhas de uma visão jurídico-institucional”, 2015), com ênfase ao estudo de sua dimensão econômico-financeira. Objetiva-se propiciar a leitura do orçamento do programa e examinar a avaliação dos resultados pelo Tribunal de Contas da União (TCU) , especialmente em relação aos indicadores do programa e à sua sustentabilidade fiscal. Parte-se da hipótese segundo a qual os mecanismos jurídicos de articulação adotados no programa são eficazes para viabilizar parte das finalidades almejadas, mas a articulação com o Tribunal de Contas da União precisa ser aprimorada para solucionar aspectos críticos do programa quanto à dimensão orçamentária.

PALAVRAS-CHAVE: Pobreza, Programa Bolsa Família, dimensão econômico-financeira, orçamento, Tribunal de Contas da União.

Clarissa Ferreira de Melo Mesquita - clamelomesquita@uol.com.br

Doutoranda em Direito Econômico e Financeiro pela Universidade de São Paulo, Faculdade de Direito - São Paulo - SP, Brasil

NOTA DE AGRADECIMENTO

Agradeço à Profa. Maria Paula Dallari Bucci, que leu e comentou versão anterior deste artigo e que me instigou a refletir sobre o tema na sua disciplina ministrada no programa de pós-graduação da Faculdade de Direito da USP. Agradeço à Mariana Bezerra Nóbrega e à Talitha Braz Bernardino, que comigo debateram intensamente 0 tema durante a referida disciplina. Sou grata também à Mateus Piva Adami, à Roberto Melo Mesquita, e aos dois pareceristas anônimos da revista, por suas críticas e sugestões.

Artigo submetido no dia 26.08.2015 e aprovado em 09.09.2016.

DOI: http://dx.doi.org/10.12660/cgpc.v21n70.55422 


\section{Abstract}

This article analyzes the Bolsa Familia Program as a public policy to combat poverty, clarifying the articulation of the actors involved and the legal framework that supports it. The program is examined based on the framework for public policy proposed by Bucci ("Quadro de referêncla de uma política pública: Primeiras linhas de uma visão jur idico-institucional",2015), deepening the study of its economic and financial dimension. The objective is to provide a reading of the program's budget and examine the evaluation of the results by the Federal Court of Accounts, especially in relation to program indicators and their fiscal sustainability. The hypothesis is that the legal articulation mechanisms adopted in the program are effective for achieving some of its goals, but the articulation with Federal Court of Accounts has to be improved to solve critical aspects of the program's budget.

Keywords: poverty, the Bolsa Familia Program, economic and financial dimension, budget, Court of Union's accounts

\section{Resumen}

En este artículo se analiza el Bolsa Familia como una política pública para combatir la pobreza, clarificando la articulación de la acción conjunta de los actores involucrados y los contornos jurídicos que la sustentan. El programa será discutido desde el marco de las políticas públicas propuestas por Bucci ("Quadro de referência de uma política pública: Primeiras linhas de uma visão juridico-institucional', 2015), profundizando el estudio de su dimensión económica y financiera. El objetivo es proporcionar una lectura del presupuesto en el programa y examinar los resultados de la evaluación por parte del Tribunal de Cuentas de la Unión, especialmente con relación a los indicadores del programa y su sostenibilidad fiscal. Se inicia con la suposición de que los mecanismos jurídicos de articulación adoptados en el programa son eficaces para realizar parte de sus propósitos, pero la articulación con el Tribunal de Cuentas de la Unión debe mejorarse para resolver aspectos críticos del programa en la dimensión presupuestaria.

Palabras clave: Pobreza, Programa Bolsa Familia, dimensión económica y financeira, presupuesto, Tribunal de Cuentas de la Union.

\section{PROPOSTA DE ANÁLISE: LEITURA DOS ASPECTOS JURÍDICOS DO PBF}

O propósito deste artigo é abordar alguns aspectos jurídicos do Programa Bolsa Família (PBF) - o mais importante programa brasileiro de combate à pobreza -, com base na proposta metodológica de análise aplicada. O ponto de partida será o isolamento dos elementos especificamente jurídicos do PBF. Essa análise terá o suporte do quadro de referência de políticas públicas elaborado por Bucci (2015), que contribui para a elaboração de um método estruturado de abordagem jurídica das políticas públicas.

Esse quadro, com base no qual se pretende ler o PBF quanto a seus aspectos jurídicos, é composto pelos seguintes elementos: 1) nome oficial do programa de ação; 2) ges- tão governamental; 3) base normativa; 4) desenho jurídico-institucional; 5) agentes governamentais; 6) agentes não governamentais; 7) mecanismos jurídicos de articulação; 8) escala e público-alvo; 9) dimensão econômico-financeira do programa; 10) estratégia de implantação; 11) funcionamento efetivo do programa; 12) aspectos críticos do desenho jurídico-institucional.

$\mathrm{O}$ artigo se estrutura em duas partes. $\mathrm{Na}$ primeira, serão apresentadas as principais características do modelo jurídico adotado pelo programa, com base na análise conjugada dos elementos do quadro de referência. $\mathrm{Na}$ segunda, será feita a análise específica e aprofundada de um dos elementos do quadro de referência: a dimensão econômico-financeira do programa, uma vez que esse aspecto tem sido negligenciado como campo 
de análise e reflexão.

O objetivo da análise da segunda parte é combinar, conjugada e articuladamente, o estudo da estrutura orçamentária do programa (sob a perspectiva que pode ser chamada de interna) com o controle do PBF pelo Tribunal de Contas da União - TCU (sob a perspectiva que pode ser denominada externa). Por uma necessidade de recorte metodológico, o estudo da perspectiva externa será centrado em torno da análise feita pelo TCU, uma das instituições brasileiras de controle externo do PBF, no Relatório Sistêmico da Função Assistência Social, TC 011.248/2014-9, que subsidia o Acórdão n. 2382/2014.

Pioneiro na análise da função da assistência social e do PBF, esse relatório é de grande importância por apresentar avaliação técnica detida do funcionamento do programa com base na interpretação do órgão de controle dos indicadores orçamentários do programa. Além disso, a leitura do TCU traz para o debate público uma questão real de viabilidade fiscal do programa, que o desafia, especialmente a longo prazo. A esse relatório e acórdão, seguiu-se um debate importante entre Ministério do Desenvolvimento Social e Combate à Fome (MDS) e TCU, que reflete a tensão entre controlado e controlador, e evidencia desafios, não apenas jurídicos, a serem enfrentados pelo programa.

A hipótese central do artigo, a ser testada, é a de que os mecanismos jurídicos de articulação adotados no programa são eficazes para viabilizar parte das finalidades almejadas, mas a articulação com o TCU, ainda que em moldes distintos, precisa ser aprimorada para solucionar aspectos críticos do programa na dimensão orçamentária.

\section{MODELAGEM JURÍDICA DO PBF}

Aqui será apresentada a análise dos aspectos jurídicos do PBF com base nos elementos que compõem o quadro de referência, com exceção do 9 (dimensão econômico-financeira do programa), objeto de reflexão posterior. Para melhor sistematização, ao longo do artigo, serão feitas referências entre parênteses aos elementos analisados em cada momento. Duas observações merecem destaque: (i) os elementos não necessariamente vão aparecer na ordem em que estão numerados no quadro; (ii) a diferenciação entre os elementos não é estanque, pois há questões do programa que se relacionam a mais de um elemento; entre parênteses optou-se por destacar apenas 0 elemento central da análise.

\section{Leitura geral do PBF}

O Programa Bolsa Família (elemento 1, nome oficial do programa de ação) é uma política pública brasileira voltada ao enfrentamento da pobreza, viabilizando a transferência de renda com a inclusão em serviços. Foi lançado no ano de 2003 (elemento 2, gestão governamental), primeiro ano do governo Luiz Inácio Lula da Silva (PT), pela unificação de programas preexistentes, com continuação no governo Dilma Rousseff (PT), no início do qual foi lançado o Plano Brasil Sem Miséria, que o PBF passou a integrar.

O PBF é o maior programa de transferência de renda condicionada (PTC; em inglês, conditional cash transfers - CCT) do mundo (Rasella et al., 2013; Coutinho, 2012) e sua 
cobertura cresceu muito ao longo dos anos. No mês de junho de 2015, o programa beneficiou 13.716.766 famílias no Brasil (Relatório de Informações - RI - Bolsa Família e Cadastro Único, 2015). Como relata Cecchini (2013, p. 370), os PTCs "têm sido um dos principais motores da inovação no âmbito da política social latino-americana nos últimos 15 anos." Esses programas surgiram em meados da década de 1990 e rapidamente se disseminaram, estando presentes atualmente em 20 países da América Latina e Caribe, beneficiando cerca de $120 \mathrm{mi}-$ Ihões de pessoas, o que representa $20 \%$ da população da região, a um custo de cerca de $0,4 \%$ do produto interno bruto (PIB) regional (Cecchini, 2013).

O PBF foi instituído pela medida provisória $132 / 03$, convertida na Lei $10.836 / 04$, regulamentada pelo Decreto 5.209/04 (elemento 3 , base normativa). Trata-se das normas estruturantes do programa, cujo funcionamento apoia-se também num feixe mais amplo de normas jurídicas, de diferentes origens, nível hierárquico e não necessariamente voltadas ao regramento específico do PBF.

Apesar do PBF ter sido concebido como parte integrante do universo mais amplo da assistência social, em grande medida, especialmente no plano federal, ele vem sendo implementado por meio de um arranjo jurídico-institucional distinto (Coutinho, 2014) (elemento 10, estratégia de implantação). 0 PBF consolidou-se em paralelo à assistência social, à margem de sua estrutura preexistente, como forma de ser blindado da carga de experiências negativas passadas, e também para desenvolver algo novo, com características próprias (Coutinho, 2014).
Na esfera federal, o MDS é responsável pela gestão do PBF, especialmente por meio da Secretaria Nacional de Renda e Cidadania (Senarc), uma das cinco secretarias que compõem a estrutura do Ministério (elemento 5 , agentes governamentais).

Importante destacar que o PBF é um dos programas sociais de combate à pobreza, mas há outros com esse objetivo ou a ele relacionados, no âmbito do MDS e dos demais ministérios (Saúde, Educação, Cidades etc.) (Relatório TCU). Na estrutura do MDS, atrelados a secretarias e gestão distintas, destacam-se os Benefícios de Prestação Continuada, os Programas Fortalecimento do Sistema Único de Assistência Social (SUAS) e a política de Segurança Alimentar e Nutricional.

O foco do PBF são as famílias pobres e extremamente pobres inscritas no Cadastro Único (CadÚnico), segundo uma regra de elegibilidade relacionada à renda familiar per capita. Consiste na transferência de renda, com condicionalidades, para famílias em situação de pobreza, de renda familiar per capita entre $R \$ 77,00$ e $R \$ 154,00$ ao mês, e de extrema pobreza, de renda familiar per capita de até $R \$ 77,00$ por mês (art. 18, caput e $\S 10$ do Decreto 5.209/14, com valores alterados pelo Decreto 8.232/14). As famílias ainda podem ser escolhidas por meio da conjunção de indicadores sociais capazes de identificar situações de vulnerabilidade social e econômica. $O$ valor do benefício é definido de acordo com o rendimento e a composição familiar. Atualmente, o PBF conta com quatro modalidades de benefícios (básico, variável, variável vinculado ao adolescente e benefício para superação da extrema pobreza), conforme art. 20 da Lei 10.836/04 e art. 19 
do Decreto 5.209/04.

O programa já nasceu desafiado pela necessidade de "unificar os programas setoriais de transferência de renda então existentes e consolidar o Cadastro Único para Programas Sociais (CadÚnico) como base de dados e de gestão do Bolsa Família" (Campello, 2013, p. 15). Ultrapassado o desafio inicial, o CadÚnico constitui atualmente importante instrumento de identificação do público-alvo do PBF, que atende a uma quantidade de famílias bastante expressiva. O gráfico 1 a seguir dimensiona a escala e o público-alvo do PBF (elemento 8, escala e público-alvo), ao longo do período de sua existência, assinalando também os valores recebidos pelas famílias beneficiárias.

GRÁFICO 1 - Evolução da quantidade de famílias beneficiárias e valores recebidos - Brasil (2004-2015)

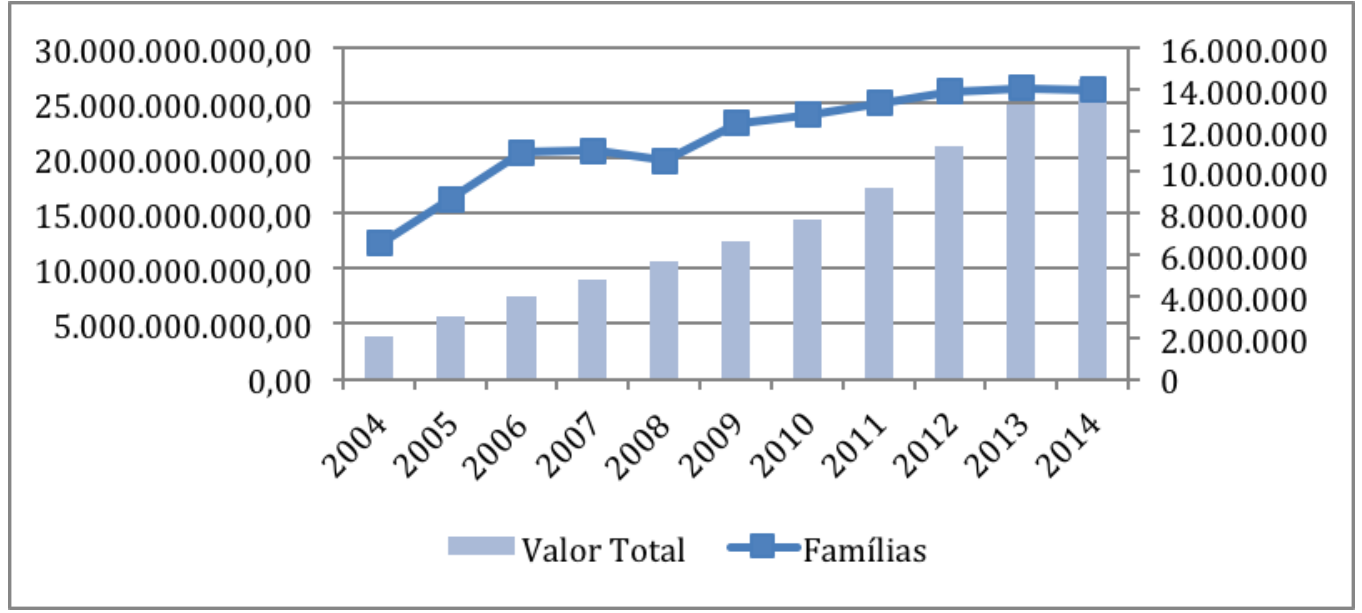

Fonte: Elaboração própria, com dados do Portal da SAGI / MI Social / MI Vetor <http://aplicacoes.mds.gov.br/sagi/miv/miv.php>.

O gráfico demonstra a grande evolução do PBF entre 2004 e 2014, tanto no número de famílias alcançadas pelo programa, quanto no valor total e ele destinado. O PBF, que iniciou em 2004 atendendo a cerca de 6,5 milhões de famílias, alcançou em 2014 cerca de 14 milhões de beneficiados. Nota-se que essa quantidade mais do que duplicou neste período de duração. Por outro lado, em 2004 foi repassado às famílias o total de $\mathrm{R} \$ 3,79$ bilhões, enquanto em 2014 o valor alcançou $\mathrm{R} \$ 27$ bilhões, sete vezes maior. $\mathrm{O}$ aumento dos valores médios transferidos deve-se às contínuas inclusões de novas famílias beneficiárias no programa e aos reajustes dos benefícios. Com isso, ultrapassa o público-alvo fixado na ocasião do lançamento do Plano Brasil Sem Miséria, em meados de 2011, de 13,8 milhões de famílias (Prestação de Contas da Presidente da República - PCPR 2013).

Além de lidar com o desafio de unificar os procedimentos de gestão e execução dos programas de transferência de renda da esfera federal, o PBF tem como objetivos promover o acesso à rede de serviços públicos, em especial de saúde, educação e assistência social; combater a fome e promover a segurança alimentar e nutricional; estimular 
a emancipação sustentada das famílias que vivem em situação de pobreza e extrema pobreza; combater a pobreza, e promover a intersetorialidade, a complementaridade e a sinergia das ações sociais do Poder Público (cf. art. 40 do Decreto 5.209/04).

Nota-se que o programa nasce para resolver carência muito profunda de milhões de famílias brasileiras, propiciando o alívio imediato da pobreza e da fome, no curto prazo. Mas seu desenho também denota o desafio de induzir o acesso de seus membros às redes públicas de saúde, educação e assistência social, priorizando a intersetorialidade. Por esse motivo, aliando-se a outras políticas, compõe uma estratégia mais ampla com a intenção de alcançar um objetivo de longo prazo e contribuir para a interrupção do ciclo intergeracional de pobreza nas famílias beneficiárias.

Para cumprir esses objetivos e metas, o programa é marcado por um desenho simples de gestão (Campello, 2013) (elemento 4, desenho jurídico-institucional). O PBF se apoia na declaração da própria renda pela família e espera romper o ciclo intergeracional da pobreza por meio da exigência do cumprimento das condicionalidades, que compõem um conjunto de ações nas áreas de educação e saúde.

Na saúde, conforme estabelece a portaria GM/MDS n. 321/2008, tem-se o acompanhamento do calendário de vacinação e do desenvolvimento e crescimento infantil para crianças menores de 7 anos; pré-natal das gestantes e acompanhamento das nutrizes (na faixa de 14 a 44 anos, conforme Neri, 2013). Na educação, exige-se que todas as crianças e adolescentes (de 6 a 17 anos) de famílias atendidas estejam matriculadas em escolas, devendo apresentar frequência escolar mínima de 85\%, com exceção dos adolescentes de 16 e 17 anos, que devem atender à frequência mínima de $75 \%$.

As famílias beneficiárias devem cumprir esses compromissos para continuar recebendo o benefício, enquanto o poder público se responsabiliza pela oferta dos serviços públicos, por meio dos sistemas públicos das respectivas áreas. Por outro lado, as condicionalidades do programa exigem articulação entre as áreas em torno da população beneficiária, que "dão ao programa um caráter intersetorial e exigem articulação estreita entre diferentes ministérios, secretarias de Estado e secretarias municipais" (Magalhães Júnior et al., 2013, p. 95).

Assim, o Ministério da Saúde (MS) é responsável por acompanhar a agenda da saúde, cujas atribuições são compartilhadas com as esferas estaduais, distrital e municipais do Sistema Único de Saúde (SUS), dentro de uma lógica de gestão descentralizada e organizativa (Magalhães Júnior et al., 2013). $\mathrm{Na}$ área da educação, incumbe ao Ministério da Educação (MEC) acompanhar a frequência escolar, o que é feito em parceria com os entes federados.

É necessário destacar que o incentivo educacional no PBF envolve apenas matrícula e frequência, sem estímulo à aprovação escolar, como fazem os programas mexicano (Oportunidades) e hondurenho (Programa de Asignación Familiar - PRAF II), conforme indica Draibe (2009).

O constante monitoramento do cumprimento das condicionalidades pelas famílias não foi 
desenhado para puni-las, a não ser depois de seguidos e injustificados descumprimentos (Coutinho, 2012). Regra geral, a Portaria GM/MDS n. 321/2008 prevê aplicação sucessiva das penalidades: 1) advertência; 2) bloqueio do benefício por um mês; 3) suspensão do benefício por dois meses; 4) suspensão do benefício por dois meses; 5) cancelamento do benefício (art. 40). Primordialmente, esse controle objetiva possibilitar que sejam desvendadas as razões do não cumprimento, via acompanhamento de assistentes sociais, e ajudar as famílias a cumprir esses compromissos (Cecchini, 2013).

Nota-se que os esforços institucionais para a implementação e desenvolvimento do PBF baseiam-se na articulação intersetorial (elemento 7, mecanismos jurídicos de articulação). As ações dos Ministérios da Saúde e Educação, setores do governo relacionados às condicionalidades, são articuladas à atuação do MDS-Senarc (elemento 5, agentes governamentais). Conforme Barbosa et al., "entre outras importantes ações, a Senarc estabelece os critérios de seleção dos beneficiários, ou seja, de quem recebe e de quanto recebe, define também o questionário do Cadastro Único e os critérios para suspensão e corte dos benefícios, entre várias outras definições de parâmetros operacionais" (2013, p. 331).

Além disso, embora a administração seja feita pelo MDS, várias outras instituições estão envolvidas, como a Caixa Econômica Federal (CEF), que é o banco público federal responsável pela gestão operacional do CadÚnico (elemento 6, agentes não governamentais). Cabe também a ela pagar os benefícios aos destinatários, com recursos da União (Tesouro Nacional), diretamente às famílias, preferencialmente às mulheres e por meio de um cartão magnético (Coutinho, 2012).

Essa articulação intersetorial é combinada com a articulação interfederativa (elemento 7 , mecanismos jurídicos de articulação). De fato, o programa federal soma esforços das diversas esferas federativas, em um contexto marcado pela definição de responsabilidades e pela diretriz de descentralização político-administrativa, que permitiu uma parceria do governo federal com governos municipais, estaduais e distrital. Deveras, conforme analisado, o trabalho de acompanhamento das condicionalidades é executado de maneira descentralizada pelos sistemas de educação e saúde (Paiva et al., 2013).

A conjugação de esforços entre entes federativos também é observada na gestão do CadÚnico. Nesse sistema, gestão e coordenação estratégica são atreladas ao MDS, mas, de forma descentralizada, os municípios realizam o cadastramento dos potenciais beneficiários, "... tendo por parâmetros as estimativas do público-alvo do programa e do cadastro" (Silveira et al., 2013, p. 307). Conforme aduz Coutinho (2012, p. 99): "Embora não haja limites para o número de potenciais beneficiários do PBF inscritos no Cadúnico, o programa prevê um teto (inicialmente de 11 milhões e atualmente de 12,5 milhões) de famílias a serem cobertas. (...) No PBF, há tetos municipais (quotas) que limitam a quantidade de beneficiários que cada cidade pode ter".

De acordo com Barbosa et al.: "o papel mais importante dos municípios é a responsabi- 
lidade pela identificação das famílias a serem beneficiadas, mediante o recolhimento das informações que compõem o cadastro" (2013, p. 331). Segundo Coutinho (2012, p. 99): " em alguns municípios, a informação é baseada em autodeclaração de renda e em outros há assistentes sociais realizando in loco a coleta de informações que são, em qualquer caso, recebidas pela Caixa Econômica Federal, encarregada dos pagamentos".

A partir das informações do CadÚnico, de responsabilidade dos agentes municipais, caberá à Caixa consolidar os números e enviá-los ao MDS, que decide quem é elegível. A CEF faz os pagamentos a partir da lista que a ela é devolvida pelo MDS (Coutinho, 2012).

Especialmente, dois mecanismos merecem ser destacados pela importância na articulação interfederativa: primeiro: termo de adesão assinado entre o MDS e os municípios brasileiros, responsável por sistematizar os compromissos a serem cumpridos pelos municípios para tornarem-se participantes do PBF. Para aderir ao PBF, cada município deve designar um gestor e precisa ter uma Instância de Controle Social (ICS), com a função de acompanhar a gestão do Cadúnico e do PBF no município. Como explica Coutinho (2014), as prefeituras brasileiras não precisaram necessariamente criar um novo órgão de controle social, pois foi permitido que conselhos já existentes no município fizessem as vezes das ICS, como instâncias designadas. Na prática, dois terços das unidades de controle social do PBF utilizam as estruturas da assistência social (Coutinho, 2014).

O segundo mecanismo de destaque é o Índi- ce de Gestão Descentralizada (IGD), criado em 2006, que reforça a capacidade gerencial dos municípios, uma vez que apresenta duas funções centrais: "mensurar a qualidade das ações de gestão do município" e "servir de base para a transferência de recursos de apoio à gestão descentralizada, que podem ser utilizados pelos municípios para a realização de ações e projetos de fortalecimento do programa, do Cadastro e do acompanhamento de condicionalidades, bem como de apoio à instância de controle social" (Paiva et al., 2013, p. 33).

Como já mencionado, a adesão dos municípios ao PBF está condicionada à criação das ICS, órgãos que realizam o controle social do programa, em nível local (Decreto 5.209/04, arts. 29 e 30). Há também ações de fiscalização feitas pelas instituições de controle externo, como Ministério Público (MP), Controladoria-Geral da União (CGU) e Tribunal de Contas da União (TCU). A fiscalização é realizada pelo MDS com base em denúncias efetuadas e documentação encaminhada pelos demais entes federados (Decreto 5.209/04, art. 33).

Importante destacar ainda que, diferentemente de outros PTCs, como o mexicano (Oportunidades) e o chileno (Puente/Chile Solidario), o programa brasileiro não prevê prazos de permanência (Draibe, 2009), pressupondo apenas a manutenção dos critérios de elegibilidade das famílias.

Avaliação jurídica da articulação do PBF: perspectiva geral

Após mais de uma década de existência do PBF, pode-se afirmar que o Bolsa Família se tornou um programa de ampla escala para 
os pobres, adquirindo estabilidade na área social, e se consolidou uma verdadeira política de Estado (Campello, 2013), que se emaranha na tessitura mais ampla do estado de bem-estar brasileiro.

Diversos estudos evidenciam que o programa tem desafios a enfrentar, mas já alcançou significativos impactos sobre as condições de vida da população beneficiada. Uma revisão da literatura evidencia alguns resultados bastante relevantes, a seguir sintetizados (elemento 11, funcionamento efetivo do programa).

São conhecidos os impactos do PBF na redução da pobreza e na diminuição da desigualdade de renda (Magalhães Junior et al., 2013), inclusive regional (Paiva et al., 2013), sendo possível que o impacto do programa explique entre 12 e $21 \%$ da redução mais recente do coeficiente de Gini (Paiva et al., 2013). A situação dos mais pobres melhorou, evidenciando que a pobreza e a extrema pobreza somadas caíram de $23,8 \%$ para $9,6 \%$ da população (Souza et al., 2013). Observa-se também que os recursos aplicados no programa têm efeito multiplicador no PIB e, segundo Paiva et al., o gasto adicional de $1 \%$ do PIB gera aumento de $1,44 \%$.

Estudos revelam impacto do PBF na dinamização da economia nacional pela criação do grande mercado consumidor interno (Magalhães Júnior et al., 2013; Jannuzzi et al., 2013) e sugerem que o desenho do programa tem sido efetivo para mantê-lo bem direcionado à população mais pobre (Paiva et al., 2013). Há evidências de que o programa não gera "efeito preguiça", bem como não tem efeito pró-natalista (Paiva et al., 2013; Jannuzzi et al., 2013, \& Oliveira et al., 2013).
Estudos demonstram ainda que não há evidências de que o programa afete a escolha ocupacional dos beneficiários entre postos formais e informais (Barbosa et al., 2013).

Também são observados avanços nas áreas da educação e saúde. Na educação, observam-se menores taxas de abandono e maiores taxas de progressão (Paiva et al., 2013, \& Oliveira et al., 2013). Na saúde, destaca-se a contribuição do programa na redução da desnutrição, da mortalidade infantil e do baixo peso ao nascer (Magalhães Júnior et al.), e no conjunto de condicionalidades de saúde, com aumento da cobertura vacinal e das consultas pré-natais (Paiva et al., 2013, \& Rasella et al., 2013).

É importante enfatizar que esses resultados favoráveis no mais das vezes se associam também a outros fatores. Por exemplo, o PBF foi um dos responsáveis pela redução da desigualdade, a qual também se relacionam fatores como "aumentos reais do salário mínimo, as aposentadorias rurais, a estabilidade monetária e o BPC [Benefício de Prestação Continuada] (...), os aumentos do gasto em educação, investimentos em capacitação para o trabalho, programas de microcrédito, alterações nos mecanismos contributivos da previdência social e a possibilidade de expansão do mercado interno e da inserção" (Coutinho, 2014, p. 276-277).

Diante dessa avaliação e da explicitação da modelagem jurídica do programa, está confirmada a hipótese inicial deste artigo: os mecanismos jurídicos de articulação adotados no programa são eficazes para viabilizar parte das finalidades almejadas.

Deveras, o sucesso do Bolsa Família, em 
boa medida, relaciona-se à boa qualidade do seu arcabouço jurídico que, no dizer de Coutinho (2012, p. 115), "vertebra" ações de desenho institucional de políticas públicas. Não é possível atribuir o resultado do programa a uma única escolha do direito, mas a uma gama delas.

Entre outras coisas, a instrumentalização jurídica do programa (i) estruturou uma rede de coordenação articulada do programa com diferentes políticas sociais, sobretudo saúde, educação e assistência social (articulação intersetorial); (ii) reforçou a conjugação de esforços dos três níveis de governo (articulação interfederativa) por meio da criação de uma rede intergovernamental responsável por sua implementação; (iii) foi fundamental na conformação do desenho jurídico-institucional do PBF, cujo sucesso também advém do Cadúnico, da gestão simples, da escolha dos agentes governamentais e não governamentais, e da estruturação em paralelo à assistência social. Por esse motivo, é possível afirmar que a criação e a evolução do Bolsa Família refletem a crescente institucionalização e integração entre programas e órgãos públicos, que são em grande medida construções jurídicas.

É certo que, como seria de se esperar, há desafios a serem enfrentados pelo programa, como sua articulação a outras políticas de assistência social (Coutinho, 2014), e a garantia de sua sustentabilidade fiscal, desafio que será especificamente abordado a seguir (elemento 12, aspectos críticos do desenho jurídico-institucional).

\section{DIMENSÃO ECONÔMICO-FINANCEIRA DO PBF}

Aqui será apresentada a análise específica e aprofundada do elemento 9 do quadro de referência. Da perspectiva econômico-financeira, serão tecidos comentários sobre a base normativa, o funcionamento efetivo do programa e os aspectos críticos do seu desenho jurídico-institucional.

\section{Leitura do orçamento do PBF}

O PBF é financiado por recursos da União (Tesouro Nacional) e por empréstimos obtidos pelo governo brasileiro junto ao Banco Internacional para Reconstrução e Desenvolvimento (Bird).

O valor direcionado ao programa tem crescido consideravelmente, alcançando mais de $\mathrm{R} \$ 27$ bilhões em 2014, valor sete vezes maior do que o repassado em 2004, como demonstra o gráfico 1, anteriormente analisado. Os gastos com a função do Estado "assistência social", nela incluído o PBF, também se revelam bastante expressivos, conforme demonstra o gráfico 2 a seguir, que representa a despesa empenhada em 2013 (valor total de $R \$ 1.930 .337$ trilhões), por função de governo, excluídos os encargos especiais ( $R \$ 987,5$ bilhões ou $51,16 \%$ do total). Dois esclarecimentos conceituais merecem ser mencionados antes da apresentação do gráfico.

Por despesa empenhada entende-se o momento a partir do qual o Estado se tornou obrigado a realizar a despesa. Com efeito, no âmbito do processo orçamentário, os passos previstos na legislação para efetivamente executar a despesa são: (i) empenho: que passa a obrigar o Estado a realizar a despesa, (ii) liquidação da despesa: fase em que se verifica se o credor tem capacidade de 
gastar o montante empenhado e se os títulos e documentos comprobatórios do crédito, como contratos e convênios, estão regulares e (iii) pagamento: que ocorre em dois momentos distintos, a ordem de pagamento de despesa e a realização do desembolso propriamente dito pela autoridade competente (Bambini de Assis, 2012).
Já a função encargos especiais "engloba as despesas que não podem ser associadas a um bem ou serviço a ser gerado no processo produtivo corrente, tais como dívidas, ressarcimentos, indenizações e outras afins, representando, portanto, uma agregação neutra" (MTO 2015, p. 32).

GRÁFICO 2 - Despesa empenhada por função de governo (2013), em R \$ milhões

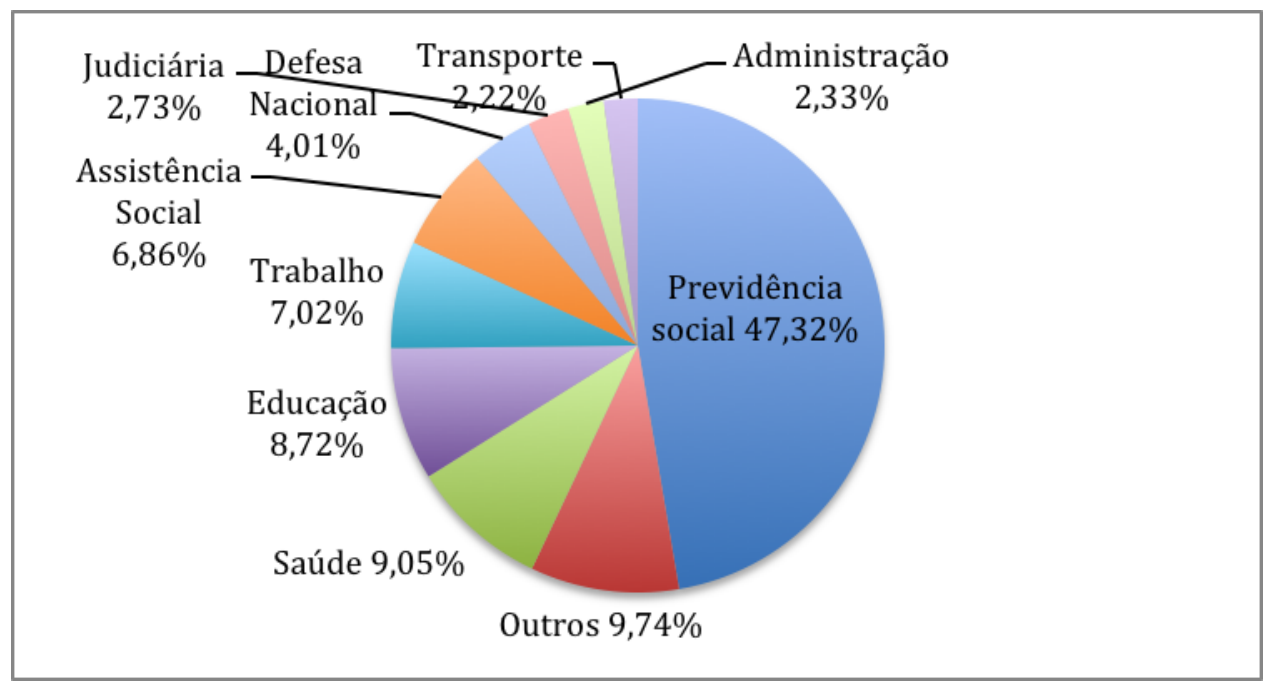

Fonte: Elaboração própria, com dados do Relatório TCU.

Constata-se do gráfico que os gastos com assistência social (R\$ 64,64 bilhões ou $6,86 \%$ do total) são menores do que os da Previdência Social, Saúde, Educação e Trabalho, mas são bastante representativos, não podendo ser considerados insignificantes em relação ao orçamento global. Além disso, outro dado merece atenção: os gastos com assistência social são principalmente com Fortalecimento do Sistema Único da Assistência Social (SUAS) $(56,40 \%)$, Bolsa Família $(38,14 \%)$ e Segurança Alimentar e Nutricional $(4,79 \%)$ (Relatório TCU). Juntos, esses três programas representam cerca de $99,33 \%$ dos gastos com a assistência social.

Esses dados demonstram que o gasto com assistência social e especificamente com o PBF é relevante, e cada vez mais. Em certa medida, essa constatação colide com a afirmação de que esse programa tem baixo custo (Paiva et al., 2013) apesar de apresentar várias externalidades positivas, que, numa situação ideal, podem fazer com que o benefício que a sociedade terá ao longo dos anos supere seu custo elevado.

Os dados da evolução orçamentária evidenciam que o PBF e a assistência social são prioridades governamentais. Deveras, como aduz Bambini de Assis, num contexto de escassez e de disputas, o orçamento é uma escolha de prioridades, pois não há recursos para atender à demanda quase infinita que 
surge sobre a questão financeira (2012). Em certa medida, esse cenário desafia a permanência de qualquer política pública, mesmo as emergentes, sobretudo em períodos de menor expansão econômica. Em 2015, por exemplo, houve corte significativo no orçamento de muitas áreas e em diversos programas sociais. Ao menos num momento inicial, o PBF foi blindado desses cortes (Foreque et al., 2015), mas sente impacto da crise, como se nota no veto da presidente ao reajuste do PBF na Lei de Diretrizes Orçamentárias (LDO) no início de 2016 (Carvalho et. al., 2016).

Assim, como aduz Cecchini, é possível afirmar que o futuro do PBF e dos PTCs dependerá das condições da economia dos diferentes países. Consolidados num período de prosperidade econômica, a diminuição dos recursos pode gerar pressão pela diminuição dos montantes das transferências e/ ou da quantidade de beneficiários (Cecchini, 2013).

A reflexão da autora e a avaliação dos dados da evolução orçamentária evidenciam o desafio de assegurar a sustentabilidade financeira do PBF, de modo a garantir cobertura e permanência temporal, para que continue cumprindo com seus objetivos. Esse desafio também foi assinalado pelo TCU, no acórdão n. 2382/2014, analisado neste artigo, relatado pelo ministro Augusto Sherman Cavalcanti, que foi acompanhado pelos demais ministros por unanimidade. Em suas razões de decidir, o ministro claramente enfatiza a necessidade de garantir a sustentabilidade fiscal do programa, para o que é necessário que o governo crie "portas de saída" (voto, p. 2).

Em linhas bastante gerais, nesse julgado, o TCU recomenda que o MDS: a) aperfeiçoe os indicadores da função assistência social do Plano Plurianual e dos relatórios de gestão de suas Secretarias; b) promova estudos para identificar ações e indicadores que auxiliem a emancipação dos beneficiários do PBF (ementa). O estudo dos indicadores remete às previsões do PBF na tríade orçamentária.

O Plano Plurianual da União (PPA) para o período de 2012 a 2015, instituído pela Lei $12.593 / 12$, em seu anexo, elenca para o programa temático Bolsa Família (Programa 2019) quatro objetivos, para os quais existem cinco indicadores (acompanhados de índices de referência), 17 metas e cinco iniciativas. A partir dessas diretrizes de ordem mais geral, as leis orçamentárias anuais fixam ações específicas. Para o PBF, a Lei 12.952/14, no suplemento 14, prevê ações específicas e os respectivos valores. A tabela a seguir resume os principais dados das leis orçamentárias. 


\section{TABELA 1 - PBF na tríade orçamentária - objetivos e iniciativas (PPA 2012-2015) e ações} (LOA 2014).

\begin{tabular}{|c|c|c|}
\hline \multicolumn{3}{|c|}{ Programa Temático 2019 - Bolsa Família } \\
\hline $\begin{array}{l}\text { Programa: } 2019 \text { Bolsa } \\
\text { Família }\end{array}$ & \multicolumn{2}{|c|}{ Valor do Programa Constante da LOA: 25.294 .890 .000} \\
\hline Objetivo (PPA) & \multicolumn{2}{|c|}{$\begin{array}{l}0374 \text { - Reforçar o acesso aos direitos sociais básicos nas áreas de Saúde, Educação e Assistência Social, } \\
\text { para ruptura do ciclo intergeracional de pobreza }\end{array}$} \\
\hline Iniciativa (PPA) & \multicolumn{2}{|c|}{$\begin{array}{l}0149 \text { - Acompanhamento das condicionalidades de saúde e educação e monitoramento das famílias com } \\
\text { descumprimentos do PBF, oferecendo diagnóstico qualificado e dinâmico da situação dessas famílias e im- } \\
\text { plementação de ações, em parceria, de aperfeiçoamento na oferta desses serviços, bem como articulação } \\
\text { de programas complementares }\end{array}$} \\
\hline Ação (LOA) & Não consta & Não consta \\
\hline Indicador (PPA) & \multicolumn{2}{|l|}{ Indicadores das Taxas de acompanhamento das condicionalidades } \\
\hline Objetivo (PPA) & \multicolumn{2}{|c|}{0375 - Aprimorar a gestão, a operacionalização e a fiscalização do Programa Bolsa Família } \\
\hline Iniciativa (PPA) & \multicolumn{2}{|c|}{$\begin{array}{l}\text { 14B - Aprimoramento e desenvolvimento de atividades terceirizadas de administração do cadastro único } \\
\text { e de benefício do PBF, bem como daquelas atividades de apoio à fiscalização, ao controle e à auditoria da } \\
\text { execução do Programa Bolsa Família }\end{array}$} \\
\hline Ação (LOA) & 20IT - Aperfeiçoamento da disseminação do PBF e do Cadastro Único & Valor: $\mathrm{R} \$ 12.500 .000$ \\
\hline Iniciativa (PPA) & \multicolumn{2}{|c|}{ 14E - Fortalecimento da capacidade de gestão descentralizada do programa Bolsa Família } \\
\hline Ação (LOA) & $\begin{array}{l}8446 \text { - Serviço de Apoio à Gestão Descentralizada do Programa Bolsa } \\
\text { Família }\end{array}$ & Valor: $\mathrm{R} \$ 603.000 .000$ \\
\hline Indicador (PPA) & \multicolumn{2}{|l|}{ Ausência de indicador } \\
\hline Objetivo (PPA) & \multicolumn{2}{|c|}{$\begin{array}{l}0376 \text { - Localizar e caracterizar as famílias consideradas como público-alvo dos programas de transferência } \\
\text { de renda e dos programas sociais do Governo Federal voltados à população de baixa renda, e realizar a } \\
\text { gestão e manutenção de suas informações socioeconômicas, por meio do desenvolvimento e aperfeiço- } \\
\text { amento de metodologias, instrumentos e sistemas de informações, com o objetivo de subsidiar o planeja- } \\
\text { mento e a implementação de políticas de combate à pobreza e à desigualdade social }\end{array}$} \\
\hline Iniciativa (PPA) & \multicolumn{2}{|c|}{$\begin{array}{l}\text { 14H - Disponibilização de informações de identificação e caracterização socioeconômica qualificadas e } \\
\text { atualizadas, de todas as famílias brasileiras de baixa renda, para elaboração de estudos e pesquisas, e } \\
\text { para o planejamento e implementação de políticas públicas e ações governamentais voltadas ao combate } \\
\text { à pobreza e à desigualdade social }\end{array}$} \\
\hline Ação (LOA) & $\begin{array}{l}6414 \text { - Sistema Nacional para Identificação e Seleção de Público-Alvo } \\
\text { para os Programas Sociais do Governo Federal - Cadastro Único }\end{array}$ & Valor: $\mathrm{R} \$ 28.500 .000$ \\
\hline Indicador (PPA) & \multicolumn{2}{|l|}{ Indicador Grau de focalização do Cadastro Único } \\
\hline Objetivo (PPA) & \multicolumn{2}{|c|}{$\begin{array}{l}0619 \text { - Melhorar as condições socioeconômicas das famílias pobres e, sobretudo, extremamente pobres, } \\
\text { por meio de transferência direta de renda e da articulação com outras políticas promotoras de emancipação }\end{array}$} \\
\hline Iniciativa (PPA) & \multicolumn{2}{|c|}{ 02ER - Transferência de renda às famílias em condição de pobreza e extrema pobreza } \\
\hline Ação (LOA) & $\begin{array}{l}8442 \text { - Transferência de Renda Diretamente às Famílias em Condição } \\
\text { de Pobreza e Extrema Pobreza (Lei 10.836, de 2004) }\end{array}$ & Valor: $\mathrm{R} \$ 24.650 .890 .000$ \\
\hline Indicador(PPA) & \multicolumn{2}{|l|}{ Indicador Taxa de atendimento às famílias pobres } \\
\hline
\end{tabular}

Fonte: Elaboração própria, com dados do PPA 2012-2015 e da LOA - 2014. 
Algumas conclusões podem ser extraídas da tabela: a) inexistem ação e recurso para concretizar o objetivo 374 ; b) não há indicadores do cumprimento do objetivo 375 , o que prejudica sua avaliação e não passou desapercebido pelo TCU. Além disso, outras conclusões podem ser obtidas da avaliação do TCU, com base na comparação do valor de referência do PPA com o valor informado no PCPR 2013, apresentado a seguir:

TABELA 2 - Indicadores selecionados do PPA - Comparação entre valores de referência e os informados

\begin{tabular}{|c|c|c|c|c|}
\hline \multirow{2}{*}{ Indicador } & \multicolumn{2}{|c|}{$\begin{array}{c}\text { Valor de referência } \\
\text { PPA }\end{array}$} & \multicolumn{2}{c|}{$\begin{array}{c}\text { Valor Informado } \\
\text { PCPR 2013 }\end{array}$} \\
\cline { 2 - 5 } & Data & Índice (a) & Data & Índice (b) \\
\hline $\begin{array}{c}\text { Grau de focalização do Cadas- } \\
\text { tro Único }\end{array}$ & $31 / 12 / 2010$ & 94 & $31 / 12 / 2013$ & 88,56 \\
\hline $\begin{array}{c}\text { Taxa de atendimento às famí- } \\
\text { lias pobres }\end{array}$ & $31 / 12 / 2010$ & 98,33 & $31 / 12 / 2013$ & 102,53 \\
\hline
\end{tabular}

Fonte: Elaboração própria, com dados do PPA 2012-2015 e do PCPR 2013.

A avaliação do TCU sobre esses dois indicadores do PPA é positiva (TC 011.248/2014-9). Segundo o Tribunal, o primeiro permite identificar se o programa está focalizado nas famílias com perfil de baixa renda, contribuindo para identificar se o programa também atinge aquelas com renda maior. $O$ segundo indicador, por sua vez, é considerado válido pelo TCU, embora não tenha alcançado com exatidão $100 \%$ e careça de atualização.

A tabela 1 ainda evidencia a diferença de valores direcionados às ações do $\mathrm{PBF}$, sendo possível notar, com base nos dados coletados, que a maior parte dos recursos com o PBF ocorre na ação 8442, transferência de renda diretamente às famílias.

Importante esclarecer que os valores das ações previstos na tabela 1 constam da LOA, portanto não necessariamente refletem os valores pagos, por alterações ao longo da execução orçamentária. No Brasil, embora alguns estudos demonstrem a necessidade de se atribuir maior eficácia às leis orçamentárias, pela própria aplicação do princípio da legalidade (Pinheiro, 2011), na prática o planejamento estatal nas leis orçamentárias ainda é, em grande medida, insuficiente por conta do caráter autorizativo do orçamento.

Por fim, a tabela 1 evidencia a inexistência de indicadores de "portas de saída" do PBF no PPA, que tampouco apresenta um objetivo voltado à emancipação ou à saída dos beneficiários do programa. Esses indicadores também não foram encontrados entre os previstos nos relatórios de gestão das Secretarias do MDS, também avaliados pelo TCU.

Em linhas gerais, nos termos do voto condutor do acórdão, essa inexistência de indicadores é bastante prejudicial, pois isso dificulta o fornecimento de informações necessárias para a tomada de decisões corretas e tempestivas, num cenário em que a evolução dos 
gastos leva à otimização da aplicação dos recursos e consequente seleção adequada dos beneficiários, bem como ao estímulo da emancipação deles. Assim, nas palavras do ministro, "é preciso estudar medidas e indicadores tendentes a incrementar as 'portas de saída' do Programa, até porque o objetivo não é manter as famílias na pobreza, mas sim emancipá-las" (voto, p. 5).

Alguns fatores explicam a preocupação do TCU com a inexistência de indicadores de "portas de saída" (voto. p. 5):

a) "na composição do índice que apura o desenvolvimento das famílias nos municípios [índice de Desenvolvimento da Família (IDF)], as dimensões da pobreza com pior avaliação são aquelas que poderiam proporcionar uma 'porta de saída' dos programas assistenciais, quais sejam, o acesso ao conhecimento e o acesso ao trabalho";

b) há o risco de que a massa de beneficiários do PBF, mantida a situação de pobreza e alcançada a idade de 65 anos, migre para o Benefício de Prestação Continuada (BPC), no valor de um salário mínimo, o que aumentaria ainda mais o impacto sobre o orçamento público;

c) a quantidade de famílias beneficiárias evolui no programa, bem como o valor médio dos benefícios, que passou de $\mathrm{R} \$$ 60,00 em 2007 para aproximadamente $\mathrm{R} \$ 150,00$ em 2013; e

d) $23,80 \%$ da população brasileira é atendida pelo PBF, percentual que supera $40 \%$ da população local em oito Estados, sendo ainda necessário considerar percentual de beneficiários do BPC e aposentados atrelados aos Regimes de Previdência.
Apesar de fugir ao escopo deste artigo analisar os indicadores dos relatórios de gestão, é importante pontuar, ainda que em linhas gerais, sua avaliação pelo TCU. Entre esses indicadores, o TCU destaca a "taxa de atendimento às famílias pobres" e o "percentual de famílias atendidas que ultrapassaram a linha de pobreza," que se baseiam na linha de extrema pobreza e pobreza definidas administrativamente, estabelecidas em $R$ \$ 70,00 e $R \$ 140,00$, valores atualizados para $R \$ 77,00$ e $R \$ 154,00$ (Decreto 8232/2014). O TCU não adentra à complexa discussão do cálculo da linha de pobreza. Porém, com base na proposta do Banco Mundial, da qual o governo afirma estar próximo ao fixar o valor de $R \$ 70,00$ ( $R \$ 77,00$, atualizado), o TCU entende que, definido o valor, ele deve ser ajustado anualmente pelo poder de paridade de compra (PPC). Isso, segundo o TCU, "... não foi feito de 2009 a junho de 2014, fazendo com que, no período, a linha de pobreza oficial se descolasse do seu significado científico e útil para uso em indicadores de desempenho" (voto, p. 3).

Conforme o relatório TCU, salientado no voto do ministro relator, com base nas inflações brasileira (IPCA) e a americana (CPI - Consumer Price Index), as linhas de pobreza e extrema pobreza poderiam ser majoradas, respectivamente, ao menos, para $\mathrm{R} \$ 100,00$ e $R \$ 200,00$, em 2013, valores acima dos atualizados ( $R \$ 77,00$ e $R \$ 154,00)$. Para o TCU, "essa constatação representa um risco de sobrestimativa do número de pobres que teriam superado a pobreza" (voto, p. 3).

Em vista da análise do TCU, fica sua mensagem: "faz-se necessário realizar um acompanhamento meticuloso e avaliar até onde 
é possível estender a concessão desses benefícios de forma sustentável" (voto, p. 5), em vista da real preocupação com a sustentabilidade fiscal do PBF.

Avaliação jurídica da articulação do PBF: perspectiva orçamentária

O Relatório Sistêmico da Assistência Social, julgado pelo TCU, primeiro relatório dessa função, como informa o TCU, tem o objetivo de oferecer ao Congresso Nacional e à sociedade brasileira um panorama da situação da assistência social.

Na prática, no entanto, o trabalho do TCU recebeu fortes críticas por parte do MDS. À sessão de julgamento do acórdão, ocorrida em 10 de setembro de 2014, seguiu-se ampla discussão envolvendo TCU e MDS. Em nota pública ("Nota de Esclarecimento do MDS"), após a sessão, esse ministério afirma que o relatório do TCU partiu de premissas erradas para chegar a conclusões equivocadas. Em passagem polêmica, ainda revela que: "o texto revela ignorância dos técnicos sobre os critérios internacionais de mensuração de pobreza, desconhecimento da legislação e até mesmo erros de cronologia que induziram os Ministros a equívoco". Para o MDS, o relatório do TCU desconsiderou as respostas e esclarecimentos técnicos por ele prestados. As críticas constantes da nota pública podem ser assim sumarizadas:

a) A linha de extrema pobreza foi instituída pelo Decreto 7.492/11, não sendo possível falar em correção desde 2009;

b) O valor de $\mathrm{R} \$ 70$ equivalia em junho de 2011 a US\$ 1,25 por dia, tendo sido atualizado para $R \$ 77$ (Decreto 8.232/14), revelando-se compatível com o parâme- tro internacional para classificar a extrema pobreza (paridade do poder de compra);

c) Os esforços de redução da pobreza não se limitaram à dimensão de renda, como comprova estudo recente do Banco Mundial, que mostra a queda da pobreza crônica multidimensional no Brasil, passando de $6,7 \%$ para $1,6 \%$ entre 2004 e 2012 ;

d) O relatório expressa posicionamento político do TCU às vésperas das eleições presidenciais, por questionar o aumento do gasto com assistência social;

e) Foi feita referência no relatório preliminar do TCU a dois projetos de lei que tramitam no Congresso Nacional, de origem do senador Aécio Neves, o que causa "estupefação";

f) O relatório do TCU adota posições simplistas e preconceituosas com o público do Bolsa Família, desconhecendo: (i) o direito à assistência social e à rede de proteção social, consolidada nos últimos anos; (ii) dados e estatísticas que mostram que a maioria dos adultos do Bolsa Família trabalha; (iii) o conjunto de esforços empreendidos pelo Brasil sem Miséria para melhorar a inclusão econômica desta população;

g) "as sugestões de aperfeiçoamento nos indicadores e técnicas de monitoramento e avaliação são sempre bem-vindas no processo de melhoria contínua das políticas públicas do MDS".

A essa nota, seguiu-se outra de esclarecimento assinada pelo ministro relator do processo, datada de 12 de setembro de 2014 ("Nota sobre o relatório da assistência social"), cujos argumentos podem ser resumidos da seguinte forma:

a) Nas conclusões do relatório aprovado 
foram considerados os dados coletados por um ano por equipe técnica preparada, e também os comentários do MDS sobre o relatório preliminar, que ficou à sua disposição por 30 dias;

b) No relatório aprovado pelo Plenário do TCU não foi apontado qualquer projeto de lei com autoria específica sobre o tema, sendo referida apenas a existência de projetos legislativos em geral;

c) O relatório reconhece a validade do parâmetro internacional definido pelo Banco Mundial (1,25 dólar por dia ajustado pelo PPC), mas “... foi verificada, na auditoria, a ausência de atualização desse parâmetro, na conversão para a moeda nacional, por um período de 5 anos, de 2009 a 2014. O dado é objetivo, basta ver o art. 10 dos Decretos 6.917/2009 e 8.232/2014";

d) "A desatualização distorce indicadores do MDS que se utilizam desse parâmetro, tais como a 'Taxa de atendimento às famílias pobres' e 'Percentual de famílias atendidas que ultrapassaram a linha de pobreza', portanto prejudicam a transparência do Programa em pontos importantes como os resultados de superação de pobreza";

e) $O$ relatório não defendeu a alteração das regras de elegibilidade do PBF pela atualização da linha administrativa da pobreza (o que geraria repercussões fiscais), mas apenas que os indicadores que usam essa linha sejam atualizados, para garantir o acompanhamento adequado do desempenho da política;

f) $O$ aumento dos gastos do programa não foi questionado, tendo em vista a real necessidade dos beneficiários;

g) O relatório indica riscos que devem ser considerados no presente para que os benefícios sejam economicamente suportados também no futuro;

h) A preocupação com as "portas de saída" do PBF diz respeito a "quebra do ciclo intergeracional da pobreza", objetivo que não conta com indicadores;

i) O relatório reconhece a importância e os benefícios das ações federais na política de inclusão social;

j) "Faz parte das atribuições constitucionais do Tribunal avaliar a administração pública e a assistência social...."

A nota do MDS também repercutiu na sessão plenária de 17 de setembro de 2014, na qual se manifestaram o Presidente do TCU, ministro João Augusto Ribeiro Nardes, o ministro relator e o ministro Marcos Bemquerer Costa, em repúdio à nota.

O embate ocorrido claramente sinaliza fragilidade na articulação entre o MDS e o TCU, e confirma a segunda parte da hipótese deste artigo, de que a articulação com o TCU precisa ser aprimorada para solucionar aspectos críticos do programa na dimensão orçamentária.

Essa articulação, no entanto, é desafiada pelo aspecto político subjacente a qualquer programa de ação e a esse em particular, a evidenciar que esse embate reflete uma disputa que é também política, e ainda pela tensão existente na relação entre controladores e controlados. Esses desafios não tornam óbvio dizer que é preciso aprimorar a articulação entre MDS e TCU, mas revelam que o problema da articulação nesse caso deve ser pensando de modo distinto. Assim, não deixa de ser um desafio do PBF o aprimoramento da articulação do MDS com o TCU, em torno dos objetivos comuns. 
É certo que essa questão envolve contornos que ultrapassam a esfera jurídica. Mas a instrumentalização jurídica também exerce papel importante, por exemplo, de aprimorar e fortalecer o diálogo institucional, e garantir que meios adequados sejam usados para se discutir tecnicamente a deliberação do TCU, que foge à nota pública usada pelo MDS.

\section{CONCLUSÕES}

Aqui o objetivo é retomar o tema central deste artigo com base nas conclusões obtidas da avaliação do PBF.

O direito cumpre um papel importante na articulação governamental necessária às políticas públicas em geral e ao Bolsa Família de forma específica. No caso do PBF, sua trajetória de sucesso é, em boa medida, consequência da sua boa instrumentalização jurídica, que combinou articulação intersetorial à articulação interfederativa. Sem dúvida, também foi fundamental para o sucesso do programa o desenho jurídico-institucional, com a consolidação do CadÚnico, a configuração de um desenho simples de gestão, a escolha dos agentes governamentais e não governamentais, e a formatação em paralelo à estrutura já existente da assistência social.

Ao longo da trajetória do programa, ele tem sido desafiado em diversos momentos e em diferentes circunstâncias. Um dos desafios a serem enfrentados é garantir sua sustentabilidade econômico-financeira, concretizando a emancipação das famílias, que é um dos objetivos primordiais do programa. Para isso, é essencial a discussão, que ultrapas- sa a esfera jurídica, sobre " as portas de saída", sendo possível afirmar que a sugestão do TCU de criação de indicadores nas leis orçamentárias pode ser uma medida eficaz.

Por outro lado, esse desafio, nada trivial, exige dos atores sociais envolvidos esforços conjuntos e coordenados, que nem sempre são facilmente atingidos, como demonstra o embate entre MDS e TCU, em torno da linha de pobreza. Esse embate reflete uma disputa que é política, além de ser fruto da tensão entre controladores e controlados.

Mesmo reconhecendo esses fatores, é possível afirmar que os caminhos a serem perseguidos para garantir sustentabilidade financeira ao programa passam pelo aprofundamento da articulação entre MDS e TCU. Constatar essa necessidade de articulação não é uma obviedade, ao menos por dois motivos. Primeiro, o aspecto político subjacente ao PBF e a tensão controlador-controlado tornam possível sustentar que, na relação MDS-TCU, o problema da articulação deve ser pensando de outro modo. Segundo, o embate entre esses órgãos traz evidentes consequências práticas para 0 programa, distanciando a possibilidade de serem encontradas soluções para os aspectos críticos do PBF na dimensão econômico-financeira e prejudicando, em última instância, o acompanhamento adequado do funcionamento da política e seu avanço como política pública central de combate à pobreza.

\section{REFERÊNCIAS}

Bambini de Assis, L G. (2012). Processo legislativo e orçamento público: Função do controle do Parlamento. São Paulo: Saraiva. 
Barbosa, A. L. N. de H., \& Corseuil, C. H. L. (2013). Bolsa Família, Escolha Ocupacional e Informalidade no Brasil. In: T. Campello, \& M. C. Neri (Orgs.). Programa Bolsa Família: Uma década de inclusão e cidadania (pp. 327-339). Brasília: Ipea. Recuperado em 26 ago. 2015, de www.ipea.gov.br/portal/images/stories/PDFs/livros/livros/livro_ bolsafamilia_10anos.pdf

Bucci, M. P. D. (2015). Quadro de referência de uma política pública: Primeiras linhas de uma visão jurídico-institucional. In: G. P. Smanio, P. T. Bertolin, \& P. C. Brasil (Orgs.), O Direito na Fronteira das Políticas Públicas. São Paulo: Páginas e Letras Editora e Gráfica.

Campello, T. (2013). Uma Década Derrubando Mitos e Superando Expectativas. In: T. Campello, \& M. C. Neri (Orgs.), Programa Bolsa Familia: uma década de inclusão e cidadania (pp. 15-24). Brasília: Ipea. Recuperado em Disponível em 26 ago. 2015, de http://www.ipea.gov.br/portal/images/stories/PDFs/livros/livros/livro_ bolsafamilia_10anos.pdf

Carvalho, D., \& Monteiro, T. (2016, 2 jan.). Dilma avalia opção para reajuste do Bolsa Familia. O Estado de São Paulo. Recuperado de http://politica.estadao.com.br/noticias/geral,dilma-avalia-opcao-para-reajuste-do-bolsa-familia, 1817324

Cecchini, S. (2013). Transferências condicionadas na América Latina e Caribe: Da inovação à consolidação. In: T. Campello, \& M. C. Neri (Orgs.), Programa Bolsa Familia: Uma década de inclusão e cidadania (pp. 369396). Brasília: Ipea. Recuperado de www. ipea.gov.br/portal/images/stories/PDFs/li- vros/livros/livro_bolsafamilia_10anos.pdf

Coutinho, D. R. (2012). O direito nas políticas sociais brasileiras: Um estudo sobre o programa Bolsa Família. In: M. G. Schapiro, \& D. M. Trubek (Orgs.), Direito e Desenvolvimento: Um diálogo entre os Brics (pp. 73-122). São Paulo: Saraiva.

Coutinho, D. R. (2014). Entre eficiência e legitimidade: $O$ Bolsa Família no desafio de consolidação do SUAS. In: A. de Á. Gomide, \& R. R. C. Pires (Eds.). Capacidades Estatais e Democracia: Arranjos institucionais de Políticas Públicas (pp. 267-293). Brasília: Ipea. Recuperado de www.ipea.gov.br/portal/images/stories/PDFs/livros/capacidades_ estatais_e_democracia_web.pdf

Draibe, S. (2009). Programas de Transferências condicionadas de renda. In: F. H. Cardoso, \& A. Foxley (Eds.), América Latina: Desafios da democracia e do desenvolvimento, $v$. 2: políticas sociais para além da crise (pp. 103-143). Rio de Janeiro: Elsevier; São Paulo: iFHC.

Foreque, F., \& Cruz, V. (2015, 22 de maio). Prioridade de Dilma, Educação deve ter corte de $R \$ 9$ bilhões. Folha de S.Paulo. Recuperado de www1.folha.uol.com.br/ mercado/2015/05/1632333-prioridade-de-dilma-educacao-deve-responder-por-13-do-corte-de-r-70-bi.shtml

Jannuzzi, P. de M., \& Rodrigues Pinto, A. (2013). Bolsa Família e seus impactos nas condições de vida da população brasileira: Uma síntese dos principais achados da pesquisa de avaliação de impacto do Bolsa Família II. In: T. Campello, \& M. C. Neri (Orgs.), Programa Bolsa Familia: uma década de 
inclusão e cidadania (pp. 179-192). Brasília: Ipea. Recuperado em 26 ago. 2015, de www. ipea.gov.br/portal/images/stories/PDFs/livros/livros/livro_bolsafamilia_10anos.pdf

Magalhães Júnior, H. M., Jaime, P. C., \& Lima, A. M. C. de. (2013). O papel do setor Saúde no Programa Bolsa Família: Histórico, resultados e desafios para o Sistema Único De Saúde. In: T. Campello \& M. C. Neri (Orgs.), Programa Bolsa Familia: uma década de inclusão e cidadania (pp. 93-107). Brasília: Ipea. Recuperado em 26 ago. 2015, de www. ipea.gov.br/portal/images/stories/PDFs/livros/livros/livro_bolsafamilia_10anos.pdf

Manual técnico de orçamento - MTO 2015. Recuperado em 26 ago. 2015, de www.orcamentofederal.gov.br/informacoes-orcamentarias/manual-tecnico/mto_2015_1a_edicao-150514.pdf

Neri, M. C. (2013). Sistemas de pagamento subnacionais baseados no bolsa família. Dez anos do programa bolsa família: Desafios e perspectivas para a universalização da educação básica no Brasil. In: T. Campello, \& M. C. Neri (Orgs.). Programa Bolsa Familia: Uma década de inclusão e cidadania (pp.125136). Brasília: Ipea. Recuperado de www. ipea.gov.br/portal/images/stories/PDFs/livros/livros/livro_bolsafamilia_10anos.pdf

Nota de esclarecimento do MDS (2015, 7 jul.). Recuperado de www.mds.gov.br/cnas/ noticias/nota-de-repudio-do-cnas

Nota sobre o relatório da assistência social - TCU (2015, 7 jul.). Recuperado de http://portal3.tcu.gov.br/portal/page/ portal/TCU/imprensa/noticias/detalhes_ noticias?noticia $=5129496$
Notas de desagravo (2015, 16 jul.). Recuperado em 16 jul. 2015, de http://portal3.tcu. gov.br/portal/page/portal/TCU/imprensa/noticias/detalhes_noticias?noticia $=5132203$

Oliveira, L. F. B. de, \& Soares, S. S. D. (2013). "Efeito Preguiça" em programas de transferência de renda? In: T. Campello, \& M. C. Neri (Orgs.). Programa Bolsa Familia: Uma década de inclusão e cidadania (pp. 341-358). Brasília: Ipea. Recuperado de www.ipea.gov. br/portal/images/stories/PDFs/livros/livros/ livro_bolsafamilia_10anos.pdf

Paiva, L. H., Falcão, \& T., Bartholo, L. (2013). Do Bolsa Família ao Brasil sem miséria: Um resumo do percurso brasileiro recente na busca da superação da pobreza extrema. In: T. Campello, \& M. C. Neri (Orgs.), Programa Bolsa Familia: Uma década de inclusão e cidadania (pp. 25-46). Brasília: Ipea. Recuperado de www.ipea.gov.br/portal/images/stories/PDFs/livros/livros/livro_ bolsafamilia_10anos.pdf

Pinheiro, L. F. V. (2011). Rumo ao orçamento impositivo: A delimitação da ação administrativa pelas leis orçamentárias. In: J. M. Conti, \& F. F. Scaff (Coords.), Orçamentos públicos e direito financeiro (pp. 385-431). São Paulo: Editora Revista dos Tribunais.

Prestação de contas da presidente da república (PCPR) 2013. Recuperado de www. cgu.gov.br/assuntos/auditoria-e-fiscalizacao/ avaliacao-da-gestao-dos-administradores/ prestacao-de-contas-do-presidente-da-republica/arquivos/2013/pcpr-2013.pdf

Rasella, D., Aquino, R., Santos, C. A. T., Paes-sousa, R., \& Barreto, M. L. (2013). Efeitos 
do Programa Bolsa Família sobre a mortalidade em crianças: Uma análise nos municípios brasileiros. In: T. Campello, \& M. C. Neri (Orgs.), Programa Bolsa Familia: uma década de inclusão e cidadania (pp.247-262). Brasília: Ipea. Recuperado de www.ipea. gov.br/portal/images/stories/PDFs/livros/livros/livro_bolsafamilia_10anos.pdf

RI Bolsa Família e Cadastro Único, 2015 Brasil. Relatórios de Informações Sociais, do Ministério do Desenvolvimento Social e Combate à Fome. Recuperado de http:// aplicacoes.mds.gov.br/sagi/Rlv3/geral/index.php? relatorio $=153 \&$ file $=$ entrada

Silveira, F. G., Campolina, B., \& Horn, R. V. (2013). Impactos do Programa Bolsa Família na alocação do tempo entre escola e trabalho de crianças e adolescentes de
10 A 18 Anos. In: T. Campello, \& M. C. Neri (Orgs.), Programa Bolsa Familia: uma década de inclusão e cidadania (pp. 305-325). Brasília: Ipea. Recuperado de www.ipea.gov. br/portal/images/stories/PDFs/livros/livros/ livro_bolsafamilia_10anos.pdf

Souza, P. H. G. F. de, \& Osorio, R. G. (2013). O perfil da pobreza no Brasil e suas mudanças entre 2003 e 2011. In: T. Campello, \& M. C. Neri (Orgs.), Programa Bolsa Familia: Uma década de inclusão e cidadania (pp. 139155). Brasília: Ipea. Recuperado de www. ipea.gov.br/portal/images/stories/PDFs/livros/livros/livro_bolsafamilia_10anos.pdf

Tribunal de Contas da União. TC 011.248/2014-9 (Relatório TCU), Acórdão $n$. 2382/2014 (Acórdão TCU). TCU - Plenário, de 10/9/2014. 